$\begin{gathered}\text { Revista do Departamento de Geografia } \\ \text { Universidade de São Paulo } \\ \text { www.revistas.usp.br/rdg } \\ \text { ISSN 2236-2878 }\end{gathered}$
V.34 (2017)

\title{
Padrões de Fotolineamentos Aplicados à Análise Morfoestrutural da Bacia do Rio Mamanguape, Paraíba
}

\section{Photo-lineament Patterns Applied to the Morphostructural Analysis of Mamanguape River Watershed, Paraíba, Northeast of Brazil}

\author{
Rhandysson Barbosa Gonçalves \\ Universidade Federal de Pernambuco \\ rhandysson@hotmail.com \\ Drielly Naamma Fonseca \\ Universidade Federal de Pernambuco \\ driellynaamma@gmail.com \\ Antonio Carlos de Barros Correa \\ Universidade Federal de Pernambuco \\ dbiase2001@terra.com.br
}

Resumo: A bacia do rio Mamanguape encontra-se no contexto fisiográfico da margem passiva do Nordeste Brasileiro, cuja história de evolução geomorfológica está relacionada aos eventos que se seguiram à abertura do oceano Atlântico Sul e a consequente separação América do Sul - África. Seus relevos são caracterizados pela alternância de altos e baixos topográficos, dispostos transversalmente à linha de costa, em concordância com os lineamentos geológicos herdados das antigas estruturas regionais subjacentes, e assim estabelecendo um padrão topográfico de grábens e horsts. Este estudo procura contribuir para a identificação das formas de relevo locais e sua evolução, que também resultou na deposição de sedimentos na área ao longo do neógeno, assim como auxiliar na compreensão de como esses depósitos sofreram reajustes superficiais em resposta às influências neotectônicas. Os fotolineamentos foram identificados com base na extração das estruturas lineares a partir do relevo sombreado de modelos digitais de elevação construídos a partir dos dados SRTM. Baseado nos resultados cartográficos, foi possível identificar que ao Norte da bacia as morfoestruturas se apresentam basculadas de forma concordante com as direções SW-NE e WSW-ENE, que representam os trends das principais zonas de cisalhamento $e$ de alojamento de plutons da área. Tais direções também exercem controle sobre a rede de drenagem. No médio e baixo curso da bacia os lineamentos exibem direção E-W como resultado da sobreimposição do trend regional ao relevo, como também das fases de reativação que se seguiram ao rift continental. Esses pulsos de rejuvenescimento também controlam o caráter assimétrico da bacia assim como o basculamento do relevo em direção à linha de costa.
Abstract: The Mamanguape River watershed lies in the physiographic context of the passive margin of Northeastern Brazil, whose geomorphological evolutionary history is linked to the events following the opening of the South Atlantic Ocean and the consequent South America vs. Africa separation. Its landforms are characterized by alternating topographic highs and lows, transversally to the coast-line, in agreement with geologic lineaments, inherited from ancient underlying structures, thus establishing a horst-graben topography. This study aims at contributing to the identification of local landforms and their evolution, which resulted in the deposition of sediments throughout the Neogene, as well as helping understand how such deposits suffered surface readjustments in response to neotectonics influences. Photolineaments were identified by means of the extraction of linear features from shaded-relief digital elevation models created from SRTM data. Based on the cartographic results, it was possible to recognize that to the North of the watershed morphostructures are tilted concordantly to the SW-NE and WSW-ENE trends of the major shear zones and pluton placement trends of the area. Such trends also exert control upon the arrangement of drainage network. In the midand lower sectors of the basin lineaments display an E-W trend, as a result of the super-imposition of the regional structural trend on the landforms, as well as of the relief reactivation following the continental rifting. Such rejuvenation pulses also control the asymmetric character of the watershed and the tilting of the landforms towards the coastline.

Keywords: Morphostructures; relief lineaments; passive margin; geomorphological evolution..

Palavras-Chave: Morfoestruturas; Lineamentos de relevo; Margem passiva; Evolução geomorfológica. 


\section{INTRODUÇÃO}

Com o advento do geoprocessamento associado ao uso de fotografias aéreas, imagens de radar e satélite as análises morfoestruturais se tornaram mais precisas, uma vez que as análises de fotolineamentos passaram a ser realizadas tanto em escala regional quanto em escala local com maior celeridade. Loczy e Ladeira (1980) afirmam que os lineamentos são condicionados pelas fraturas, falhas, planos de acamamento, de xistosidade, foliação e lineações e dependendo do tipo de litologia, um ou um conjunto desses fatores atuarão como condicionantes da compartimentação morfoestrutural.

Jordan e Schott (2005) afirmam que, em termos geomorfológicos, os fotolineamentos representam as variações na altimetria das feições, bem como o alinhamento de cristas, estruturas escarpadas, trechos retilíneos de drenagem e vales. Eles refletem as principais linhas de fraquezas regionais, podendo indicar a ocorrência de estruturas geológicas, atestando uma possível influencia estrutural e/ou tectônica na evolução da paisagem. Na área estudada, os lineamentos estão de acordo com o trend regional identificado por Neves et al. (2000) e Bezerra et al. (2008), e obedecem a uma imposição geotectônica derivada dos eventos ocorridos no passado geológico e reativados no período da separação América do Sul - África.

A ação desses fatores é observável em escala local (dezenas de quilômetros quadrados), estando esses comumente articulados às zonas de cisalhamentos em escala regional. A compreensão dos elementos condicionantes dos lineamentos, assume, portanto, extrema importância na análise morfoestrutural e geomorfológica, pois pode expressar em diferentes graus, a influência da estrutura geológica na evolução da paisagem, bem como apontar indícios e até corroborar a vigência de reativações tectônicas durante o Quaternário (GONTIJO, 1999; HIRUMA et al., 2001; MODENESIGAUTTIERI et al., 2002; HIRUMA, 2007).

O presente trabalho tem como objetivo identificar os fotolineamentos na bacia do rio Mamanguape, (Figura 1) Estado da Paraíba, através da análise dos padrões de orientação e comprimento dos fotolineamentos, bem como sua distribuição espacial, como subsídio à compreensão do papel do condicionamento morfoestrutural e morfotectônico sobre a evolução geomorfológica.

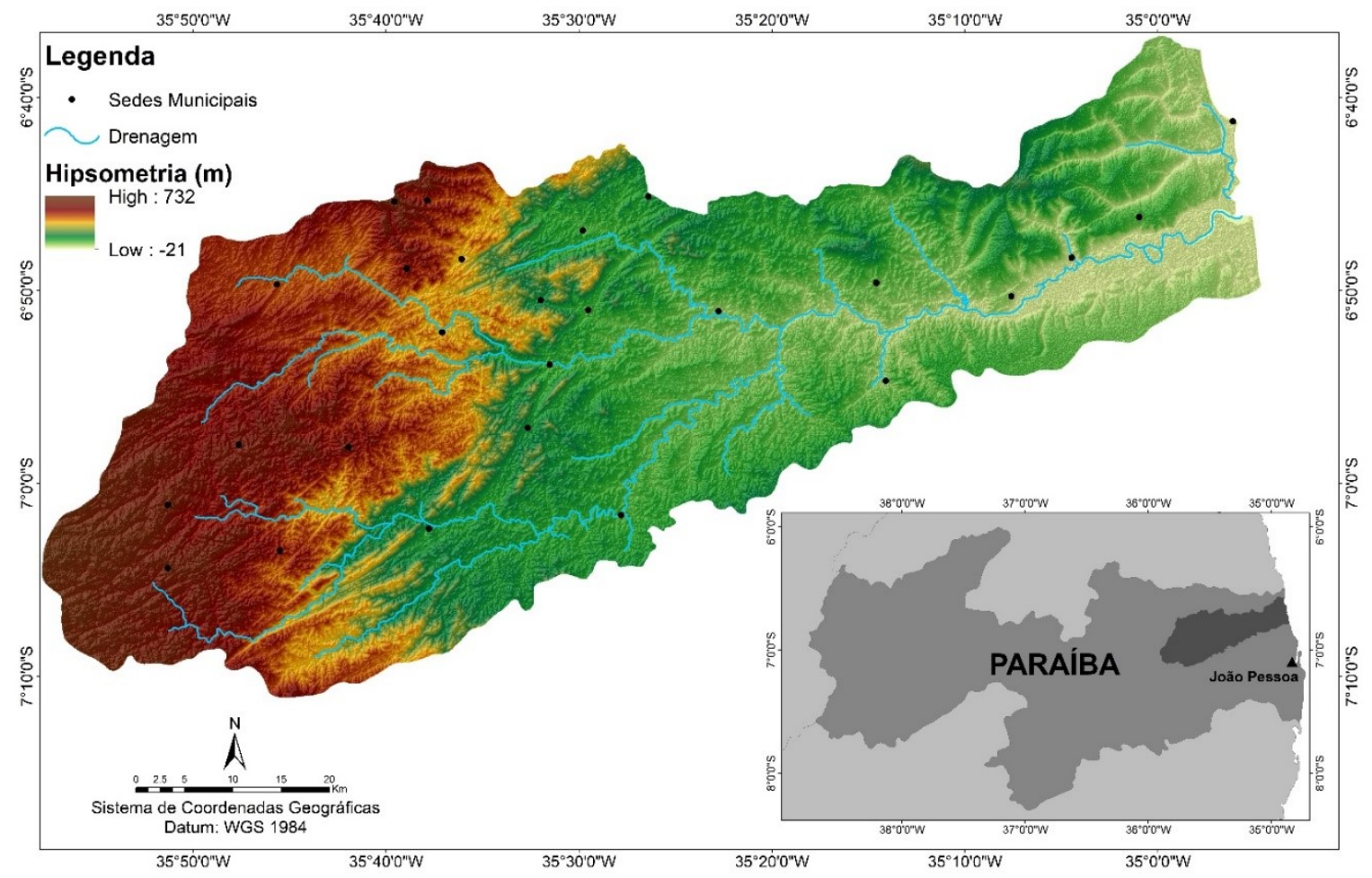

Figura 1: Mapa de localização da Bacia hidrográfica do rio Mamanguape. Fonte: Autor, 2017. 


\section{GEOLOGIA REGIONAL}

Geologicamente (Figura 2), a área localiza-se na porção norte da Bacia Paraíba, abrangendo a faixa costeira compreendida entre o Lineamento Patos (Falha de Mamanguape), a norte e a Falha de Itabaiana, a sul. Barbosa et al. (2003) e Brito Neves et al., (2009) afirmam que a bacia se insere na sub-bacia Miriri. Para além da porção inserida sobre os terrenos geológicos sedimentares das bacias marginais costeiras, a bacia do rio Mamanguape também drena o embasamento cristalino da Província Borborema. Este é composto, segundo Brito Neves et al. (2000), por terrenos deformados do Neoproterozoico do Terreno Alto Pajeú (VAN SCHMUS et al., 2011), intercalados com rochas do terreno Alto Moxotó e São José do Campestre de idade Paleoproterozoica (BRITO NEVES et al.., 2001; BRITO NEVES et al.., 2013).

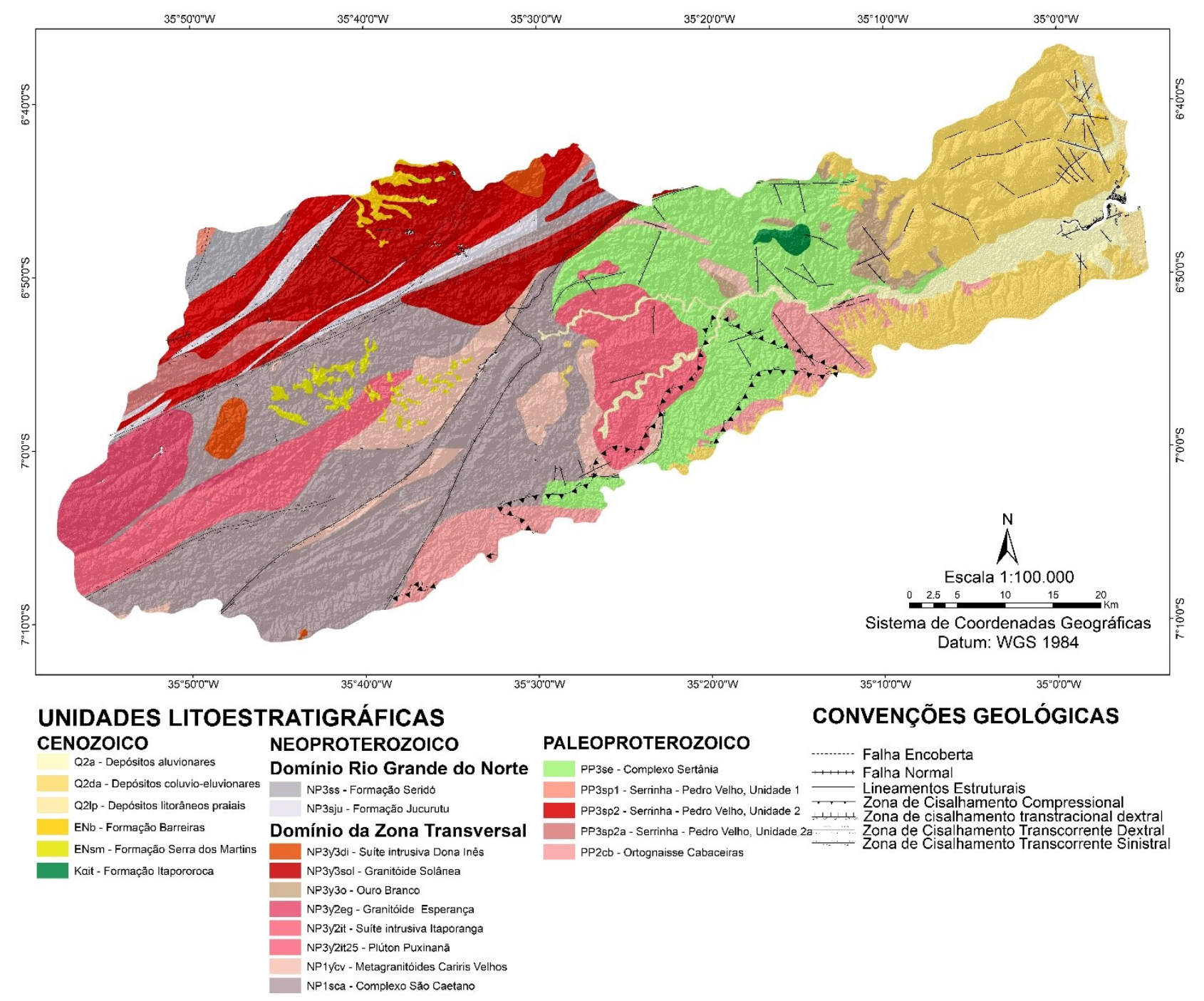

Figura 2: Mapa Geológico da Bacia do Rio Mamanguape. Fonte: Adaptado de CPRM (2008); (2014a); (2014b); (2015); (2017).

Tectonicamente a área conta com fraturas e zonas de cisalhamento dispostas transversalmente à linha de costa. Estas estruturas datam provavelmente do final do ciclo Brasiliano ( $540 \mathrm{Ma})$, sendo suas expressões superficiais recobertas pelos sedimentos Fanerozóicos da Bacia Paraíba. Estas estruturas possuem feições de geometria sigmoidal milonitizadas, atreladas à época da colagem do continente Gondwana ocidental, originadas pela fusão de diversas microplacas e terrenos deformados do final do Ciclo Brasiliano (JARDIM DE SÁ, 1994; BRITO NEVES et al. 2000). Entretanto, a última grande atividade tectônica ocorrida neste setor, com influência marcante sobre a hierarquização das grandes unidades do relevo, ocorreu já no Fanerozóico (Mesozoico), durante a separação do supercontinente, resultando na abertura de rifts marginais e abortados, ao longo do Cretáceo (MATOS, 1992; ALMEIDA et al., 2000; BRITO NEVES et al., 1999, 2000, 2001). 
Boa parte das bacias costeiras do Nordeste oriental apresentam sequências sedimentares pósrift, desenvolvidas durante o principal estágio da abertura do Oceano Atlântico. Apesar dos falhamentos pós-rift terem sidos menos intensos que os da fase inicial da abertura do oceano, esses foram de fundamental importância para a preservação das sequências sedimentares pós-cretáceas (BEZERRA e VITA-FINZI, 2000; BARRETO et al., 2002; BEZERRA et al., 2008).

Brito Neves et al., (2004) asseveram que a reativação pós-cretácea possui uma natureza distencional de direção E-W e ENE-WSW, responsável pelo desenvolvimento da bacia por afundamento crustal a partir da existência de um sistema tafrogênico inicial. Não obstante, autores apontam que a movimentação tectônica não resulta apenas dos esforços distencionais, mas também de esforços gravitacionais que ocorreram ao longo do Cenozóico, evidenciados pelo desajuste topográfico de várias unidades estratigráficas (BEZERRA et al., 2008; ROSSETTI et al., 2009; TAVARES, 2010).

As nascentes da bacia estão assentadas sobre unidades geológicas pertencentes ao Terreno São José do Campestre que vão desde o Arqueano até o Neoproterozoico, no setor noroeste, apresentando litotipos desde os micaxistos da Formação Seridó, às intrusões neoproterozoicas de granodioritos e granitos porfiríticos que servem como marcadores temporais da orogênese brasiliana. Ocorrem ainda na área granodioritos cálcio-alcalinos paleoproterozóicos e as três unidades litodêmicas do Paleoproterozoico do Complexo Serrinha - Pedro Velho formadas por biotitahornblenda ortognaisses e migmatitos (FERREIRA e SANTOS, 2000; SANTOS et al., 2002; GUIMARÃES et al., 2008). Sobre alguns setores da alta bacia, recobrindo rochas plutônicas, encontram-se também coberturas siliciclásticas cenozóicas associadas à Formação Serra do Martins, constituídas por arenitos localmente conglomeráticos e cauliníticos, além da ocorrência de crostas lateríticas (MORAIS NETO e ALCKMIN, 2001).

Estendendo-se de oeste para leste, a bacia insere-se nas unidades geológicas do Domínio da Zona Transversal, especificamente no Terreno Alto Pajeú, caracterizado por litologias neoproterozóicas das sequencias vulcano-sedimentar a sedimentar imaturas do Complexo São Caetano, cortadas e intercaladas por corpos tabulares e pequenos stocks de ortognaisses bastante diversificados, aludidos ao Ciclo Cariris Velhos, do início do Toniano (BRITO NEVES et al.., 1995; 2000; 2005; KOZUCH, 2003). Do mesmo modo do Terreno São José do Campestre, ocorre localmente sobre as rochas plutônicas o recobrimento pela Formação Serra dos Martins e Formação Barreiras, em ambos os casos considerados como testemunhos do soerguimento do Planalto da Borborema (OLIVEIRA, 2008).

No setor leste da bacia do rio Mamanguape, já na área pertencente à Bacia da Paraíba, ocorrem os afloramentos da Formação Barreiras, caracterizados pela presença de fáceis típicas de sistema fluvial intercaladas com fáceis transitórias para leques aluviais (ALHEIROS, 1988). Quanto aos Depósitos Aluvionares, estes compõem os terraços fluviais, várzeas e as planícies de inundação, podem atingir até dez metros de altitude e normalmente são constituídos por areia, cascalho e argilas de proveniência continental (XAVIER, 2007). Por fim ocorrem ainda sobre a paisagem as Coberturas Colúvio-eluvionares estruturadas por depósitos detríticos, semi-consolidados ou inconsolidados, compostas por materiais argilosos com seixos clássicos, e de típica coloração avermelhada e alaranjada, recobrindo unidades mais antigas, responsáveis por estruturar a porção superior dos modelados mais rebaixados (CPRM, 2014).

\section{MATERIAIS E MÉTODOS}

\subsection{Análise de Fotolineamentos}

$\mathrm{Na}$ interpretação de produtos a partir do sensoriamento remoto, deve-se levar em conta que os lineamentos não se restringem apenas a um tipo de movimento tectônico ao longo de toda sua extensão nem a um único ciclo tectônico. Também deve-se atentar para que uma zona de falha pode dar origem a vários lineamentos paralelos e subparalelos (VENEZIANI, 1987). Etchebehere et al.. (2007) afirmam ainda que os lineamentos de relevo, em particular, são feições topográficas lineares observáveis em imagens fotográficas que também podem evidenciar descontinuidades estruturais. 
A partir do avanço tecnológico, o sensoriamento remoto tornou-se uma ferramenta bastante importante nos estudos de análise estrutural dos lineamentos. Queiroz et al. (2000) afirmam que foi a partir da década de 1970 que o termo lineamento sofreu uma redefinição, em substituição ao termo feição linear, passando a caracterizar feições mapeáveis da superfície terrestre, simples ou compostas, de traço retilíneo ou suavemente curvo, que diferem de feições adjacentes e presumivelmente refletem um fenômeno de superfície.

Afim de fazer uma melhor avaliação da análise dos lineamentos utilizou-se as imagens de radar SRTM (Shuttle Radar Topography Mission) com resolução espacial de 30 metros, da qual se obteve o Modelo Digital de Elevação (MDE). A partir deste foram gerados quatro mapas de rugosidade do relevo levando-se em conta os azimutes de iluminação a $45^{\circ}, 90^{\circ}, 315^{\circ}$ e $360^{\circ}$ no intuito de se obter uma análise mais abrangente das feições retilíneas, no software ArcGIS 10.1.

Para cada mapa de rugosidade gerou-se um mapa de lineamento de relevo, utilizando os parâmetros sugeridos por Liu (1984), que identifica linhas de segmentos de escarpas, alinhamentos de cristas e vales, trechos da drenagem e depressões alongadas. Foi possível também, representar as estruturas dúcteis de caráter regional, com a indicação de foliações, lineações, eixos e flancos de dobras representados por relevo positivo ou negativo de acordo com a proposta de Amaro e Strieder (1994).

No cálculo da direção e comprimento dos fotolineamentos foi utilizado o software SPRING 5.2.7, onde foi possível representar estes dados em diagramas de rosetas para cada azimute de iluminação, o que totalizou 8 diagramas.

\section{RESULTADOS E DISCUSSÔES}

$\mathrm{Na}$ área da bacia do rio Mamanguape, foram identificados 1.549 fotolineamentos, observando-se uma maior concentração de fotolineamentos nas direções SW-NE, WSW-ENE, SE-NW, ESE-WNW, SSE-NNW, E-W, ao passo que os maiores comprimentos estão nas direções WSW-ENE e SW-NE (Figura 3).

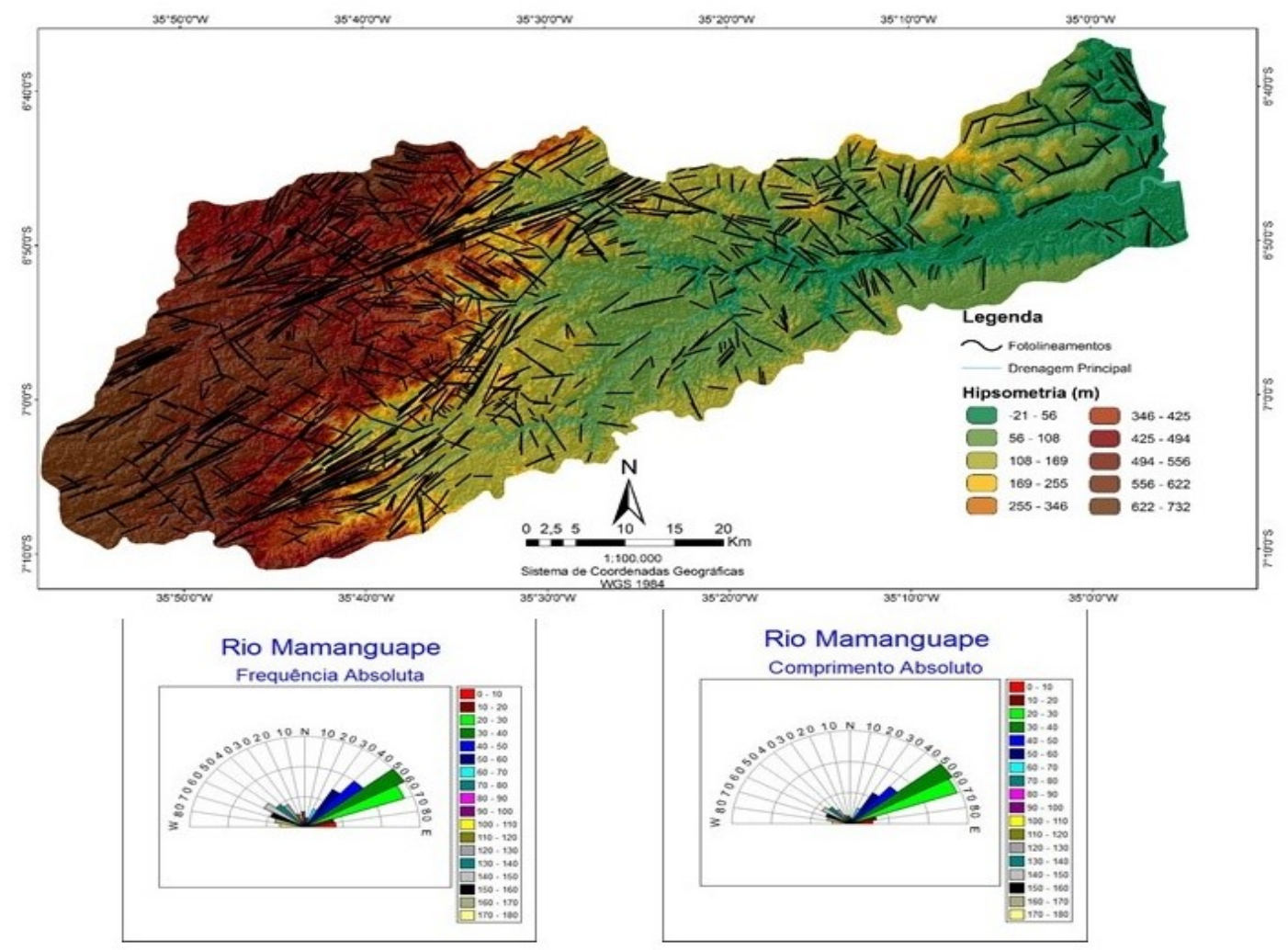

Figura 3: Mapa de fotolineamentos observáveis na Bacia do Rio Mamanguape. 
Analisando a densidade dos fotolineamentos, a Figura 4 mostra que as maiores concentrações estão na porção noroeste da bacia do rio Mamanguape, em especial sobre uma faixa de orientação SW-NE correspondente ao Lineamento Patos. No setor sul-sudoeste prevalecem as orientações SSW-NNE e WSW-ENE correspondentes às Zonas de Cisalhamento Matinhas e Zona de Cisalhamento Galante, concordantes com o trend regional. Outro setor onde observa-se uma concentração de fotolineamentos é a porção leste da bacia, área de ocorrência dos sedimentos da Formação Barreiras e dos depósitos colúvio-eluvionares, com uma faixa de orientação SW-NE e outra SSE-NNW, a primeira relacionada ao trend regional do Lineamento Patos e a segunda às falhas e fraturas de mesma direção, perpendiculares ao sistema de grábens e horsts presente na bacia, especificamente o gráben do Mamanguape.

A partir do esquadrinhamento dos padrões de fotolineamentos, percebe-se que o mesmo possui particularidades de acordo não somente com os trends, mas também com as características geológicas pertinentes a cada setor da bacia, evidenciando possíveis parâmetros evolutivos. Neste sentido, foi possível distinguir quatro domínios de fotolineamentos.

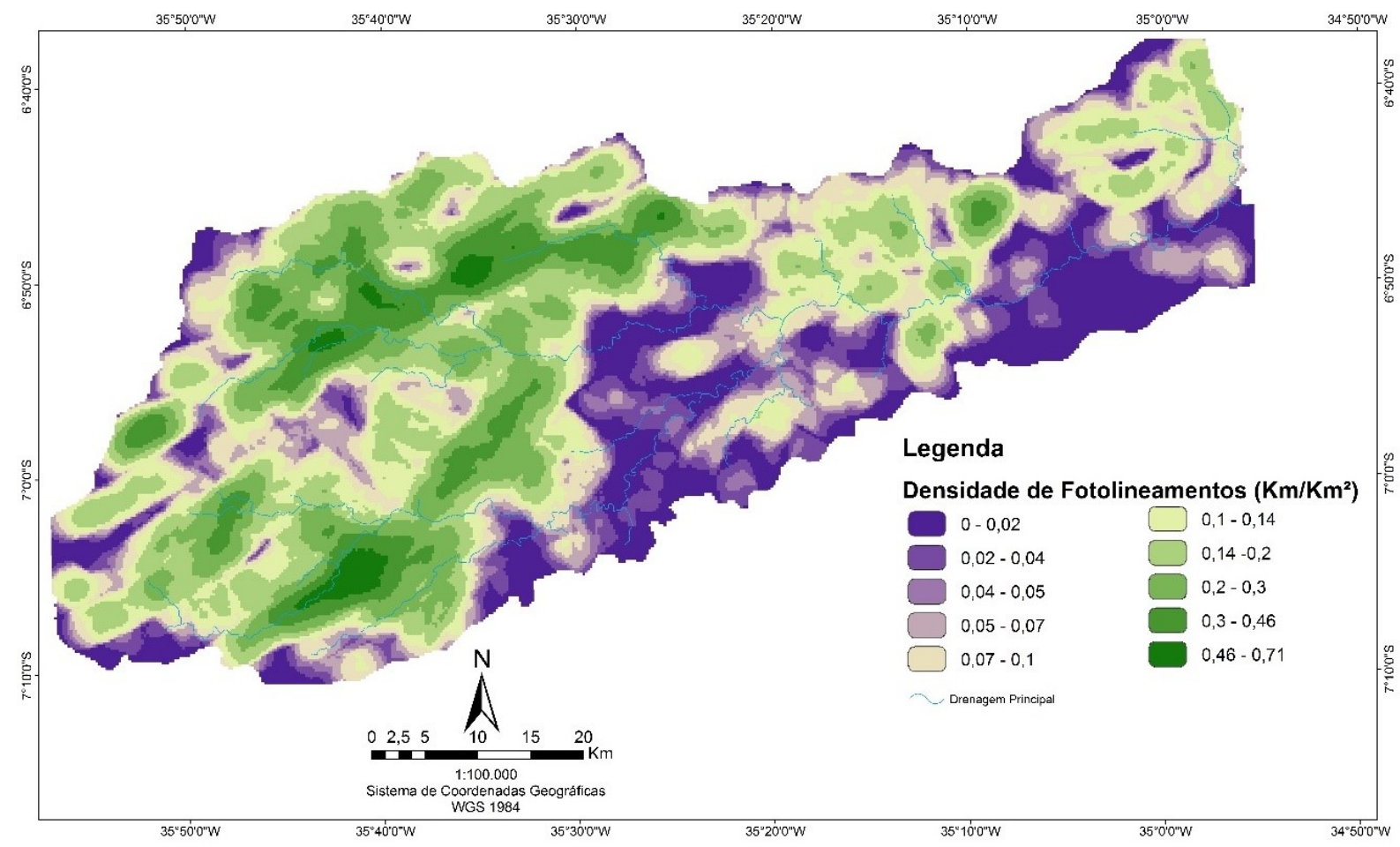

Figura 4: Mapa de densidade de fotolineamentos.

O primeiro domínio abrange a região a noroeste da bacia, a norte da Zona de Cisalhamento Patos e a sul da Zona de Cisalhamento Casserengue, pertencente ao compartimento morfoestrutural do Planalto da Borborema que Corrêa et al.. (2010) denominaram de Cimeira Estrutural São José do Campestre. Os fotolineamentos nesta região possuem um direcionamento preferencial de SW-NE e WSW-ENE (Figura 5), traduzidos em horsts que produzem formas alongadas na paisagem. Entretanto, o basculamento das superfícies de cimeira dessas formas se dá em direção WNW-SSE, concordante com o posicionamento da drenagem que apresenta um aspecto retilíneo, encaixado em grábens.

O segundo domínio de fotolineamentos estende-se também em uma orientação preferencial SWNE e WSW-ENE (Figura 6), abrangendo a região mais alta da bacia na porção oeste. Este setor se insere morfologicamente na Cimeira Estrutural São José do Campestre, entre a Zona de Cisalhamento Patos e a Zona de Cisalhamento Galante, caracterizada por superfícies altas que por vezes estão capeadas pelos sedimentos neogênicos da Formação Serra dos Martins. Há ainda a ocorrência de cristas alongadas estruturadas em rochas migmatíticas, acompanhando zonas de cisalhamento secundárias de direção SSW-NNE, também com aspecto morfológico de pequenos grábens e horsts em sequência. 


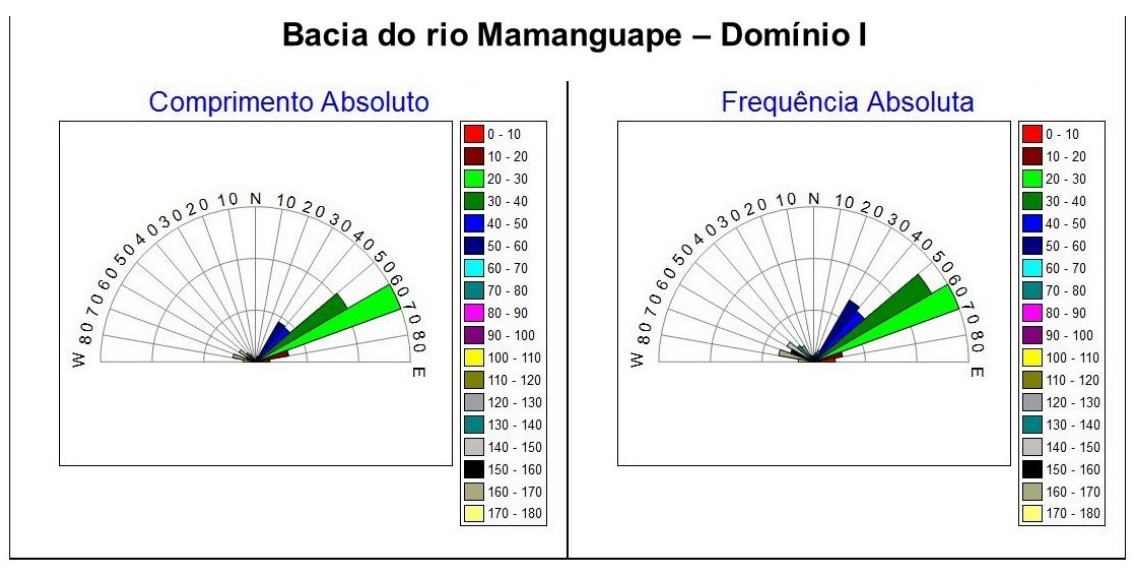

Figura 5: Diagramas em rosetas representando os comprimentos e as frequências absolutas do primeiro domínio.

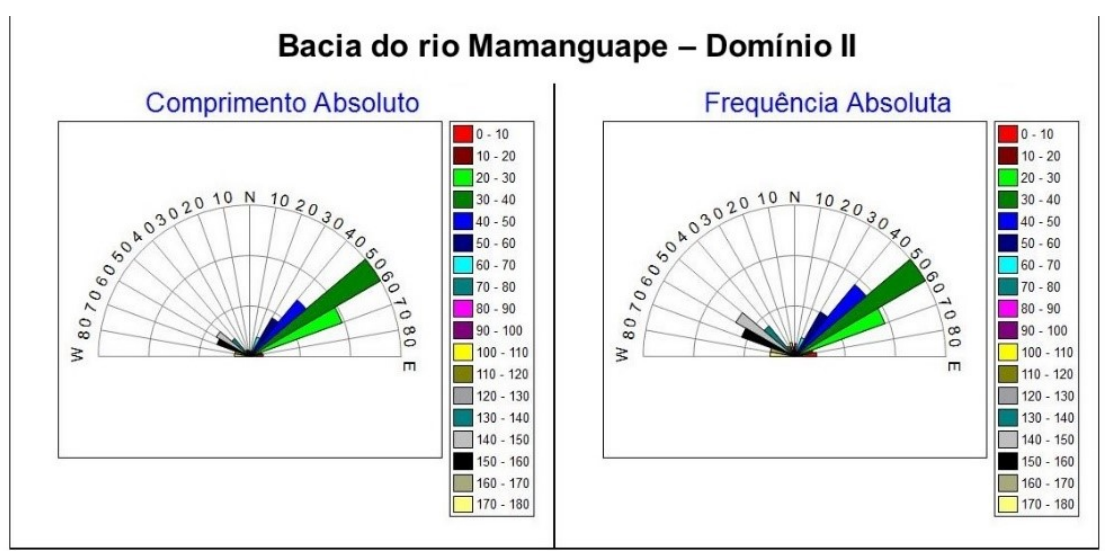

Figura 6: Diagramas em rosetas representando os comprimentos e as frequências absolutas do segundo domínio.

Ao contrário do que ocorre no primeiro Domínio, mesmo havendo um direcionamento preferencial da drenagem superimposto ao trend das formas - ou seja SE-NW -, o que corrobora a interpretação de assimetria da bacia do rio Mamanguape, as formas possuem um escalonamento orientado pelo trend gerado pela Zona de Cisalhamento Patos em direção à costa. O terceiro domínio de fotolineamentos encontra-se sobre o compartimento morfoestrutural denominado de Depressão PréLitorânea (CORRÊA et al., 2010), caracterizado por uma topografia mais suave - com cotas abaixo dos 200 metros -, estruturadas a partir da intercalação de rochas metamórficas do Paleoproterozoico e Neoproterozoico, além de intrusões plutônicas. O Domínio é também caracterizado por ser uma área transitória para os depósitos cenozoicos da costa.

Assim como o domínio anterior, este apresenta um escalonamento das estruturas em direção à linha de costa de direção SW-NE. Entretanto, ao contrário do que ocorre nos dois domínios anteriores, este apresenta uma frequência absoluta de fotolineamentos mais diversa, sem obedecer a um único direcionamento. Neste caso, há uma maior concentração de fotolineamentos de direção W-E, SW-NE, SSW-NNE e WSW-ENE (Figura 7) corroborando a influência direta da Zona de Cisalhamento Patos, onde é possível observar um relevo mais acentuado em formato de cristas, ao passo que os direcionamentos SE-NW, ESE-WNW e SSE-NNW relacionam-se a falhas e/ou fraturas que subordinam a drenagem e à formação de possíveis hemi-grábens.

No domínio dos depósitos Cenozóicos, na porção leste da bacia do rio Mamanguape, os fotolineamentos foram extraídos sobre os depósitos da Formação Barreiras e Pós-Barreiras (OCHOA, et al., 2013). O relevo neste setor é marcado por formas tabulares, pouco ou muito dissecadas, com vales bastante entalhados, associados à unidade morfoestrutural Planalto Sedimentar Costeiro como descrita por Corrêa et al.., (2010). Identificou-se um predomínio de fotolineamentos de direção SSE-NNW e SE-NW (Figura 8), relacionados à instalação do sistema de 
grábens e horsts das bacias marginais do Nordeste, resultando no reafeiçoamento da drenagem nos horsts, que passam a estabelecer a sua incisão em direção perpendicular à direção dos falhamentos que os definem.

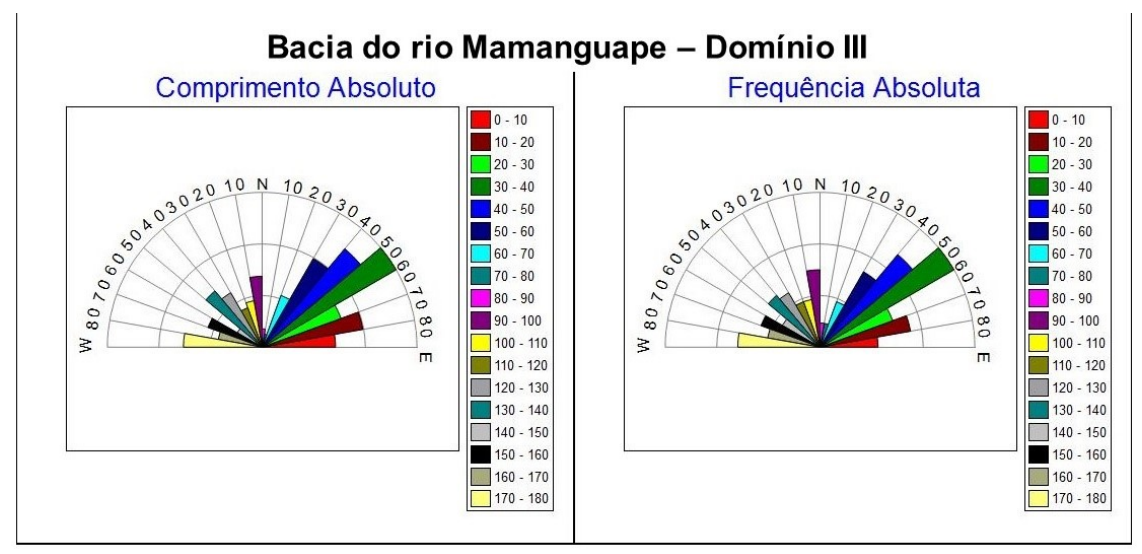

Figura 7: Diagramas em rosetas representando os comprimentos e as frequências absolutas do terceiro domínio.

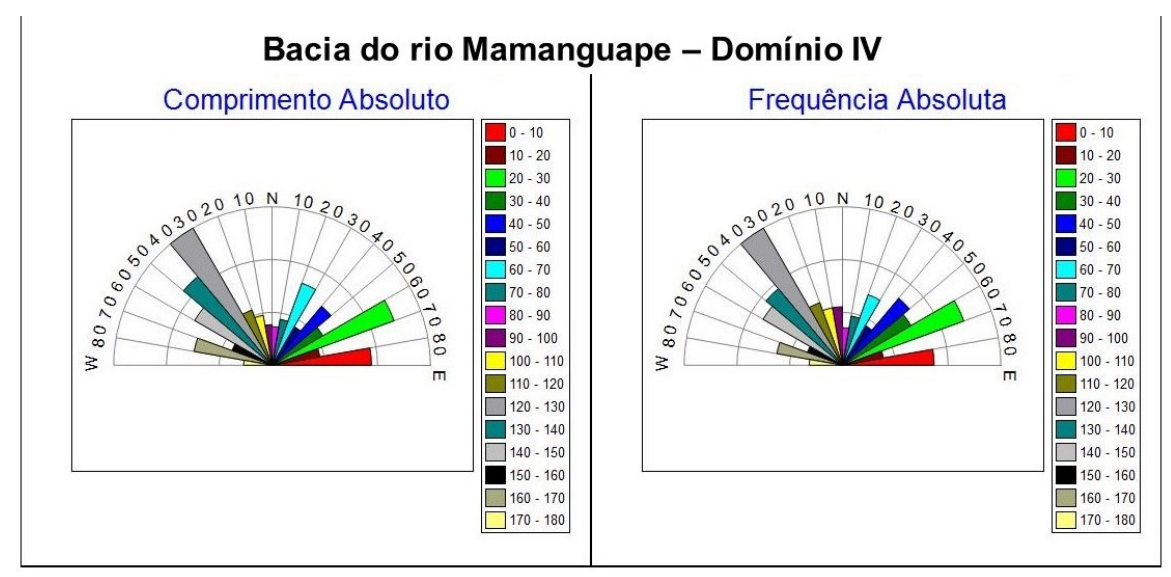

Figura 8: Diagramas em rosetas representando os comprimentos e as frequências absolutas do quarto domínio.

Por conseguinte, ao longo do domínio dos depósitos Cenozóicos verifica-se uma maior variação na distribuição das orientações dos fotolineamentos, com a presença constante de feições retilíneas de direção SW-NE, W-E e SSW-NNE correlatas ao estabelecimento do Gráben do Mamanguape (atual nível de base local). Os fotolineamentos refletem diretamente a disposição desajustada dos blocos em relação ao basculamento das estruturas na direção NW-SE, que se traduz no aspecto assimétrico da bacia e na dissecação dos blocos elevados.

\section{CONSIDERAÇÕES FINAIS}

Os padrões de fotolineamentos identificados para a bacia do rio Mamanguape definem quatro compartimentações bastante contrastantes, diretamente correlacionadas à compartimentação litoestrutural: o domínio do embasamento Paleoproterozoico, à noroeste, onde as direções SW-NE e WSW-ENE predominam de forma marcante, com a presença de feições alongadas em maior densidade e basculamento das formas na direção WNW-SSE, estabelecendo os primeiros indícios de assimetria da rede de drenagem. O segundo domínio, composto por uma litologia Neoproterozoica à oeste e sudoeste da bacia, também possui um direcionamento preferencial para SW-NE e WSWENE estando, neste caso, as feições escalonadas na mesma direção, compostas por cristas alongadas estruturadas em litologias mais resistentes. 
O terceiro domínio também possui um direcionamento e um escalonamento na direção SW-NE. Configura-se como uma área de transição entre o embasamento Proterozóico e os depósitos cenozoicos, com topografia mais suave. Entretanto possui uma distribuição de fotolineamentos mais diversa também com direcionamentos SE-NW, ESE-WNW e SSE-NNW, traduzido no encaixe da drenagem quase que perpendicular às áreas mais altas. Finalmente, o quarto domínio expressa as mesmas características de distribuição dos fotolineamentos do terceiro domínio, com a diferença de que ali estes padrões se manifestam sobre os depósitos cenozoicos. Os direcionamentos SSE-NNW e SE-NW estão diretamente relacionados ao trend regional, ao passo que os direcionamentos perpendiculares a estes (SE-NW, ESE-WNW e SSE-NNW) subordinam-se de forma secundária, aos padrões de fraturamentos neotectônicos.

Por fim, o trabalho aponta para a ocorrência de um controle litoestrutural evidente sobre a bacia do rio Mamanguape, que se manifesta sobre a rede de drenagem, orientando o sentido dos vales de acordo com as principais zonas de fraqueza geradas pelas zonas de cisalhamento. As observações realizadas permitem ainda inferir um controle neotectônico sobre o relevo da bacia, manifestado sobretudo por meio da deformação dos capeamentos sedimentares Cenozóicos que ora se encontram alçados a níveis altimétricos correlatos às formas do embasamento cristalino à montante, e apontam para a manutenção da flexura da borda continental ao longo do Neógeno. Essa deformação está claramente evidenciada na desconexão altimétrica dos sedimentos da Formação Barreiras, uma vez que estes estruturam um compartimento de relevo cuja superfície de cimeira ocorre em cotas semelhantes, e por vezes até mais elevadas, àquelas da Depressão Pré-litorânea a oeste. A Depressão Pré-litorânea integra o Piemonte do Planalto da Borborema, estruturada em rochas cristalinas da Província homônima, tendo sido a área fonte dos depósitos continentais neogênicos que ora estruturam o Planalto Sedimentar Costeiro.

\section{REFERÊNCIAS}

ALHEIROS, M. M.; LIMA FILHO, M. F.; MONTEIRO, F. A. J; OLIVEIRA FILHO, J. S. Sistemas deposicionais na Formação Barreiras no Nordeste Oriental. In: CONGRESSO BRASILEIRO DE GEOLOGIA, 35, 1988, Belém. Anais... Belém: SBG, v.2, p.753-760. 1988.

ALMEIDA, F. F. M.; BRITO NEVES, B. B.; CARNEIRO, C. D. R. The origin and evolution of the South American platform. Earth-Science Reviews, v. 50, p. 77-111, 2000.

AMARO, V. E.; STRIEDER, A. J. Análise de fotolineamentos e padrões estruturais em imagens de satélite. In: CONGRESSO BRASILEIRO DE GEOLOGIA, 38, 1994, Balneário Camboriú. Anais... Balneário Camboriú: SBG, p.443-444, 1994.

BARBOSA, J. A.; SOUZA, E. M.; LIMA FILHO, M. F.; NEUMANN, V. H. A estratigrafia da Bacia da Paraíba: uma reconstituição. Estudos Geológicos, UFPE, v. 13, p.89-108, 2003.

BARRETO, A. M.; BEZERRA, F. H. R.; SUGUIO, K.; TATUMI, S. H.; YEE, M.; PAIVA, R. P.; MUNITA, C. S. Late Pleitocene marine terrace deposits in northeastern Brazil: sea-level change and tectonic implications. Paleogeography, Paleoclimatology, Paleoecology, v.179, p.57-69, 2002.

BEZERRA, F. H. R.; BRITO NEVES, B. B.; CORREAA, A. C. B.; BARRETO, A. M. F.; SUGUIO, K. Late Pleistocene tectonical-geomorphological development within a passive margin - The Cariata trough northeastern Brazil. Geomorphology, v. 97, p. 555-582, 2008.

BEZERRA, F. H. R.; VITA-FINZI, C. How active is a passive margin? Paleoseismicity in northeastern Brazil. Geology. v.28, n.7, p.591-594, 2000.BRITO NEVES, B. B.; VAN SCHMUS, W. R.; HACKSPACHER, P. C.; SANTOS, E. J. Geocronologia da Província Borborema: os fatos e as questões abertas. In: SIMPÓSIO DE GEOLOGIA DO NORDESTE, 16, Recife. 1995a. Boletim... Recife, SBG/NE, v.14, n.2, p.410-413, 1995.

BRITO NEVES, B. B.; CAMPOS NETO, M. C.; FUCK, R. A. From Rodinia to western Gondwana: na approach to the Brasiliano-Pan African Cycle and orogenic collage. Episodes, v.22, n.3, p.155-166, 1999.

BRITO NEVES, B. B.; SANTOS, E. J.; VAN SCHMUS, W. R. Tectonic history of the Borborema Province. In: CORDANI U. G.; MILANI, E. J.; THOMAZ FILHO, A.; CAMPOS, D. A.(eds.) Tectonic evolution of the South America. $3^{\text {st }}$ International Geological Congress, p.151-182, 2000.BRITO NEVES, B. B.; CAMPOS NETO, M. C.; VAN SCHMUS, W. R.; SANTOS, E. J. O sistema Pajeú- 
Paraíba e o maciço São José do Campestre no leste da Borborema. Revista Brasileira de Geociências, v. 31, p. 1-15, 2001.

BRITO NEVES, B. B.; RICCOMINI, C.; FERNANDES, T. M.G.; SANT'ANNA, M. G. O sistema trafogênico Terciário do saliente oriental nordestino na Paraíba: um legado Proterozóico. Revista Brasileira de Geociências, v.34, n.1, p.127-134, 2004.

BRITO NEVES, B. B.; VAN SCHMUS, W. R.; KOZUCH, M; SANTOS, E. J.; PETRONILHO, L. A Zona Tectônica Teixeira Terra Nova - ZTTTN - Fundamentos da geologia regional e isotópica. Revista do Instituto de Geociências, v.5, n.1, p.57-80, 2005.

BRITO NEVES, B. B.; ALBUQUERQUE, J. P. T.; COUTINHO, J. M. V.; BEZERRA, F. H. R. Novos dados geológicos e geofísicos para a caracterização geométrica e estratigráfica da Sub-bacia Alhandra (Sudeste da Paraíba). Revista do Instituto de Geociências, v. 9, n.2, p.63-87, 2009.

BRITO NEVES, B. B.; SPRÖESSER, W. M.; PETRONILHO, L. A.; SOUZA, S. L. Contribuição à Geologia e à Geocronologia do Terreno Rio Capibaribe (TRC, Província Borborema). Revista do Instituto de Geociências - USP, Série Científica, São Paulo, v.13, n.2, p.97-122, 2013.

CPRM - Serviço Geológico do Brasil. Folha Solânea (SB -25 - Y_A - IV). In: GUIMARAES, I. P.; BITTAR, S. M.; SILVA, J. M. R.; SILVA, F. M. J.; BRITO, D. A.; ALCANTARA, V. C. V. Programa Geologia do Brasil - Relatório técnico, Etapa Final. Ministério de Minas e Energia/UFPE, 2008, 72p.

CPRM - Serviço Geológico do Brasil. Folha Cabedelo (SB -25 -Y -A - VI). In: NEUMANN, V. H. M. L.; GUERRA, N. C.; MELO, C. B.; MENEZES FILHO, J. A.; LIMA, R. P. Programa Geologia do Brasil - Relatório técnico, Etapa Final. Ministério de Minas e Energia/UFPE, 2014a, 48p.

CPRM - Serviço Geológico do Brasil. Folha Solânea (SB -25 - Y - A - IV). In: GUIMARAES, I. P.; BITTAR, S. M.; FARIAS, D. J. S.; SILVA, L. H. N.; YADAVA, R.; NERY, N. Programa Geologia do Brasil - Carta. Ministério de Minas e Energia/UFPE, 2014b.

CPRM - Serviço Geológico do Brasil. Folha Campina Grande (SB - $25-Y-C-I)$. In: RODRIGUES, S. W. O.; MEDEIROS, V. C. Programa Geologia do Brasil - Relatório técnico, Etapa Final. Ministério de Minas e Energia/CPRM, 2015, 80P.

CPRM - Serviço Geológico do Brasil. Folha Sapé (SB -25 - Y - C - II). In: GUIMARAES, I. P.; BITTAR, S. M.; ALMEIDA, C. N.; YADAV, R. Programa Geologia do Brasil - Relatório técnico, Etapa Final. Ministério de Minas e Energia/UFPE, 2017, 75p.

CORREAA, A. C. B.; TAVARES, B. A. C.; MONTEIRO, K. A.; CAVALCANTI, L. C. S.; LIRA, D. R. Megageomorfologia e morfoestrutura do Planalto da Borborema. Revista do Instituto Geológico, v.31, n.1/2, p.35-52, 2010.

ETCHEBEHERE, M. L. C.; SAAD, A. R.; FULFARO, V. J. Análise de bacia aplicada à prospecção de água subterrânea no planalto acidental paulista, SP. Geociências, São Paulo: UNESP, v.26, n.3, p.229-247, 2007.

FERREIRA, C. A.; SANTOS, E. J. Programa Levantamentos Geológicos Básicos do Brasil. Jaguaribe SE. Folha 24-Z. Estados do Ceará, Rio Grande do Norte e Pernambuco. Escala 1:500.000. Gelogia e Metalogênese. CPRM. CD-ROM, 2000.

GUIMARÃES, I. P.; BITTAR, S. M. B.; SILVA, J. M. R.; SILVA, F. M. J. V.; ARAÚJO, D. B.; ARRUDA, S. D. D'A.; ALCANTARA, V. C. Solânea - sb.25-y-a-iv, ESCALA 1:100.000: nota explicativa. Programa Geologia do Brasil - Levantamentos Geológicos Básico. Paraíba: CPRM - Serviço Geológico do Brasil. 2008. 64p.

GONTIJO, A. H. F. Morfotectônica do médio vale do Rio Paraíba do Sul: região da Serra da Bocaína, Estados de SP e RJ. São Paulo, SP. 1999. 259f. Tese de Doutorado, Universidade de São Paulo, 1999.

HIRUMA, S. T.; RICCOMINI, C.; MODENESI-GAUTTIERI, M. C. Neotectônica do Planalto de Campos do Jordão, SP. Revista Brasileira de Geociências. V.31, n.3, p.375-384, 2001.

HIRUMA, S. T. Significado morfotectônico dos planaltos isolados da Bocaina. 205f. Tese (Doutorado em Geologia) - Instituto de Geociências, Universidade de São Paulo, 2007. 
JARDIM DE SÁ, E. F. A Faixa Seridó (Província Borborema, NE Brasil) e o seu significado geodinâmico na Cadeia Brasiliana/Pan-Africana. Brasília, DF. 1994. 803f. Tese de Doutorado Universidade de Brasília, 1994.

JORDAN, G.; SCHOTT, B. Applicatin of wavelet analysis to the study of spatial pattern of morphotectonic lineaments in digital terrain models. A case of study. Remote Sensing of Environment, v.94, p.31-38, 2005.

$\mathrm{KOZUCH}, \mathrm{M}$. Isotopic and trace element geochemistry of early neoproteroozoic gneissic and metavulcanic rocks in the Cariris Velhos orogen of the Borborema Province, Brazil, and their learing on tectonic setting. Kansas. 2003. Thesis (PHd) - University of Kansas, 2003.

LIU, C. C. Análise estrutural de lineamentos em imagens de Sensoriamento Remoto: aplicação do Estado do Rio de Janeiro. São Paulo, SP. 1984. 175f. Tese de Doutorado, Universidade de São Paulo, 1984.

LOCZY, L.;LADEIRA, E. A. Geologia estrutural e introdução à geotectônica. São Paulo: Edgard Blücher,1980, p. 528.

MATOS, R. M. D. History of the northeast Braziliam rift system: kinematic implications for the break up between Brazil and west Africa. In: CAMERON, N. R.; BATE, R. H.; CLURE, V. S. (eds.). The oil and gas habitants of the South Atlantic. Geol. Soc. Espec. Publ., v.153, p.55-73, 1992.

MODENESI-GAUTTIERI, M. C.; HIRUMA, S. T.; RICCOMINI, C. Morphotectonics of a high plateau on the northwestern flank of the Continental Rift of Southern Brazil. Gomorphology, v.43, p.257271, 2002.

MORAIS NETO, J. M. e ALKMIM, F. F. A deformação das coberturas terciárias do Planalto da Borborema (PB-RN) e seu significado tectônico. Revista brasileira de Geociências 31(1), p.95-106. 2001

NEVES, S. P.; VAUCHEZ, A.; FERAUD, G. Tectono-thermal evolution, magma emplacement and Shear zone development in the Caruaru área (Borborema Province, NE Brazil). Precambrian Research, v.99, p.1-32, 2000.

OCHOA, F. L.; GÓES, A. M.; ROSSETTI, D. M.; SAWAKUCHI, A. O.; CASSINI, L. V.; COUTINHO, J. M. V. Discriminação dos depósitos cenozoicos da parte emersa da Bacia Paraíba (NE, Brasil) por meio de minerais pesados e granulometria. Brazilian Journal of Geology, v.43, n.3, p.555-570, 2013.

OLIVEIRA, R. G. Arcabouço geofísico, isostasia e causas do magmatismo Cenozóico da Província Borborema e da sua margem continental. Natal, RN. 400f. Tese de Doutorado, Universidade Federal do Rio Grande do Norte, 2008.

QUEIROZ, C. L.; MENESES, P. R.; JOST, H. Lineamentos em imagens de sensores remotos e seu significado estrutural nos terrenos granito-greentone belt de Orixás (GO). Revista Brasileira de Geociências, v.30, n.4, p.655-662, 2000.

ROSSETTI, D. M.; VALERIANO, M. M.; BEZERRA, F. H. R.; BRITO NEVES, B. B.; GÓES, A. M. Caracterização morfológica da porção sul da Sub-bacia Alhandra, Bacia Paraíba, com base em dados SRTM: contribuição na compreensão do arcabouço estrutural. In: SIMPÓSIO BRASILEIRO DE SENSORIAMENTO REMOTO, 14. Natal. Anais INPE, p. 3325-3332, 2009.

SANTOS, E. J.; FERREIRA, C. A.; SILVA JÚNIOR, J. M. F. Geologia e Recursos Minerais do Estado da Paraíba. Programa Levantamentos Geológicos Básicos do Brasil. CPRM, 2002, 234P.

TAVARES, B. A. C. A participação da morfoestrutura na gênese da compartimentação geomorfológica do gráben do Cariatá, Paraíba. Recife, PE. 137f. 2010. Dissertação de Mestrado, Universidade Federal de Pernambuco, 2010.

VAN SCHMUS, W.R., KOZUCH, M., BRITO NEVES, B.B., 2011. Precambrian history of the Zona Transversal of the Borborema Province, NE Brazil: Insights from Sm-Nd and U-Pb geochronology. Journal of South American Earth Sciences. v. 31, p. 227-252.

VENEZIANI, P. Análise de movimentos de tectônica rúptil e rúptil-dúctil através da interpretação de produtos de sensores remotos na região do Espinhaço Meridional (MG): 
uma correlação com processos evolutivos. São Paulo, SP. 1987. 186f. Tese de Doutorado, Universidade de São Paulo, 1987.

XAVIER, M. W. Caracterização geomorfológica sedimentológica e aspectos ambientais do litoral de Goiana, Pernambuco. Recife, PE. 2007. 76f. Dissertação de Mestrado - Universidade Federal de Pernambuco, 2007. 